\title{
Evaluation of Pathological Findings of COVID-19 by Minimally Invasive Autopsies: A Single Tertiary Care Center Experience from India
}

\author{
Vikarn Vishwajeet ${ }^{1} \quad$ Abhishek Purohit ${ }^{1} \quad$ Deepak Kumar $^{2} \quad$ Vijay Parag $^{2}$ Swapnil Tripathi ${ }^{2}$ \\ Tanuj Kanchan ${ }^{3}$ Nikhil Kothari ${ }^{4} \quad$ Naveen Dutt $^{5}$ Poonam Abhay Elhence ${ }^{1}$ \\ Pradeep Kumar Bhatia ${ }^{4}$ Vijaya Lakshmi Nag ${ }^{6} \quad$ Mahendra Kumar Garg $^{2}$ Sanjeev Misra ${ }^{7}$
}

${ }^{1}$ Department of Pathology and Lab Medicine, All India Institute of Medical Sciences (AlIMS), Jodhpur, Rajasthan, India

${ }^{2}$ Department of General Medicine, All India Institute of Medical Sciences (AlIMS), Jodhpur, Rajasthan, India

${ }^{3}$ Department of Forensic Medical and Toxicology, All India Institute of Medical Sciences (AlIMS), Jodhpur, Rajasthan, India

${ }^{4}$ Department of Anaesthesia, All India Institute of Medical Sciences (AlIMS), Jodhpur, Rajasthan, India

5 Department of Pulmonary Medicine, All India Institute of Medical Sciences (AIIMS), Jodhpur, Rajasthan, India

${ }^{6}$ Department of Microbiology, All India Institute of Medical Sciences (AlIMS), Jodhpur, Rajasthan, India

7Department of Surgical Oncology, All India Institute of Medical

Sciences (AlIMS), Jodhpur, Rajasthan, India

\author{
Address for correspondence Poonam Abhay Elhence, \\ MD, Department of Pathology and Lab Medicine, Basni \\ Industrial Area Phase-II, Jodhpur 342005, Rajasthan, India \\ (e-mail: poonamelhence@gmail.com).
}

\begin{abstract}
Keywords

- autopsy

- COVID-19

- pathology

- SARS-CoV-2

Objectives The 2019 novel coronavirus (2019-nCoV) has spread across the globe with more than 6 lakh deaths. Clinical autopsies are important to understand the pathobiology of the disease.

Materials and Methods Autopsy techniques have been modified to be minimally invasive autopsies in all COVID-19 positive cases, and tissue biopsies were sampled from lungs, liver, and bone marrow within an hour after death. Detailed histological analysis was performed in the sampled tissues, along with immunohistochemistry. Patients' clinical records were collected.

Statistical Analysis Descriptive statistics were used to summarize data.

Results Of the 21 cases studied, $76.2 \%$ patients were $\geq 60$ years of age, $80.9 \%$ were males, and $85.7 \%$ had co-morbidities. Histopathological analysis revealed diffuse alveolar damage (including exudative and organizing phase) in $88.9 \%$ cases. Microthrombi were seen in $44.4 \%$ cases. Additional findings include viral cytopathic changes, metaplastic change in the epithelium, intra-alveolar hemorrhage, and pulmonary edema. Liver showed centrizonal congestion with hepatocytic loss, lobular inflammation,

published online June 28, 2021

DOI https://doi.org/

10.1055/s-0041-1730750 ISSN 0974-2727

C 2021. The Indian Association of Laboratory Physicians.

This is an open access article published by Thieme under the terms of the Creative Commons Attribution-NonDerivative-NonCommercial-License, permitting copying and reproduction so long as the original work is given appropriate credit. Contents may not be used for commercial purposes, or adapted, remixed, transformed or built upon. (https://creativecommons.org/licenses/by-nc-nd/4.0/). Thieme Medical and Scientific Publishers Pvt. Ltd. A-12, 2nd Floor, Sector 2, Noida-201301 UP, India
\end{abstract}


steatosis, Kupffer cell hypertrophy, and sinusoidal neutrophilic infiltration, while significant portal infiltrate and cholestasis were absent to minimal. Bone marrow revealed hemophagocytosis in $60 \%$ cases.

Conclusion Incorporation of minimally invasive autopsies provides an effective method to study the pathological findings in COVID-19 deaths in resource-constrained settings. Presence of pulmonary microthrombi in a significant number of cases supports the vascular events, apart from the characteristic diffuse alveolar damage, as an important pathogenic mechanism for lung injury in COVID-19 infections. Histopathological findings in the liver and bone marrow suggest indirect insult to these organs, related to circulatory and/or hyperinflammatory response to viral infections.

\section{Introduction}

The 2019 novel coronavirus (2019-nCoV) or the severe acute respiratory syndrome corona virus 2 (SARS-CoV-2) has spread from its origin in Wuhan City of the Hubei Province of China to the rest of the world. ${ }^{1}$ Till August 9 of the year 2020, more than 19 million cases of coronavirus disease 2019 (COVID-19) and more than 7 lakh deaths were reported across the world, while the number of deaths is continuously increasing. ${ }^{2}$ In India, the first confirmed case of COVID-19 was reported on January 30, 2020, and since then, the virus has spread across the country with many cities becoming the epicenters of the pandemic. ${ }^{3}$ Till August 9, 2020, more than 2 million cases of COVID-19 and more than 43,000 deaths were reported from India. ${ }^{2}$

The pathobiology of the disease is poorly known, and significant efforts have been made to understand the disease process worldwide. Based on clinical characteristics, it has been observed that 20\% of COVID-19 patients develop severe disease with high mortality rate and are associated with older age and immunosuppression. ${ }^{4,5}$ Clinical autopsies are known to have a vital role in developing an understanding of the disease process. A few case series have been published from Western world. However, there is dearth of literature on histopathological findings in COVID-19 deaths from the Indian subcontinent. At our center, we have made an effort to study COVID-19 deaths on histopathology by doing minimally invasive autopsies. In this report, we are reporting histopathologic findings of 21 cases.

\section{Material and Methods}

The study was conducted in a tertiary care center in Western India. In COVID-19 pandemic, clinical autopsy protocols have been modified and minimally invasive autopsies have been performed in all COVID-19 positive cases where we could obtain consent from the next of kin of the deceased. Similar procedure was adopted for COVID-19 suspect cases whose COVID-19 reverse transcriptase polymerase chain reaction (RT-PCR) testing report was not available at the time of death. Minimally invasive autopsy was done in the form of postmortem core needle biopsies from visceral organs including lungs, liver, and bone marrow within an hour after death. Random sampling was done from both the lungs and involving all the lobes. This was done with all biosafety measures taking help of last radiographic images and surface anatomical landmarks. The tissue specimens were kept in neutral buffered formalin for 48 hours and then processed with standard biosafety measures.

Hematoxylin and eosin-stained sections were prepared, and slides were reviewed by three pathologists (V.V., A.P., and P.A.E.). Special stains (Periodic acid-Schiff, Masson's trichrome, and Elastic Van Gieson) were done, wherever required. Semi-quantitative assessment of histopathological findings was performed in lung and liver parenchyma ( 0 = absent, 1 = mild, 2 = prominent). Immunohistochemistry was performed for TTF-1 (Thermo Fisher Scientific, 8G7G3/1, 1:100), p63 (Dako, DAK-p63, ready to use), CD3 (Dako, polyclonal, ready to use), CD4 (Dako, 4B12, ready to use), CD8 (Dako, DK25, ready to use), CD20 (Thermo Fisher Scientific, L26, 1:250), and CD68 (Thermo Fisher Scientific, KP-1, 1:400) in lung tissue while CD68 (Thermo Fisher Scientific, $\mathrm{KP}-1,1: 400)$ alone was performed in liver and bone marrow. Electronic medical records of all cases were reviewed retrospectively and patients' clinical details (including presenting complaints, presence of co-morbidities, duration symptom onset to death and duration of hospital stay) and results of laboratory investigations (including complete blood count, X-ray chest, D-dimer, lactate dehydrogenase, and liver function tests) were noted. Descriptive statistics were used to summarize the data, whenever applicable. The study was approved by the Institutional Ethics Committee of the Institute (certificate reference number AIIMS/IEC/2020-21/3058).

\section{Results}

\section{Clinical Features and Laboratory Findings}

We obtained consent in 24 deceased cases wherein minimal autopsies were performed. Of these 24 cases, 3 cases were negative on RT-PCR testing for SARS-CoV-2. The clinical presentation included shortness of breath (100\% cases), fever $(71.4 \%)$, and cough (52.4\%). The median age of COVID-19 positive cases was 63 years (range $28-73$ years). 


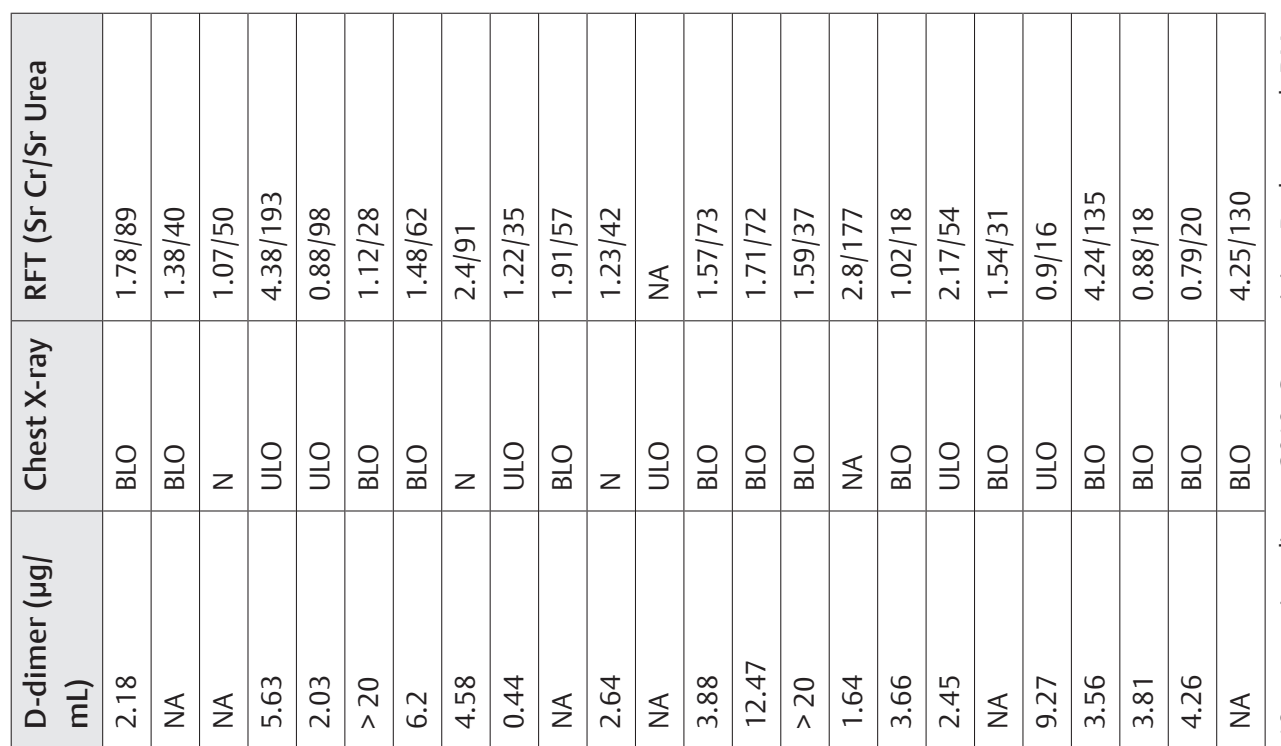

$\sum \stackrel{\pi}{0}$

苛岂

造

要 它 흔 它絰

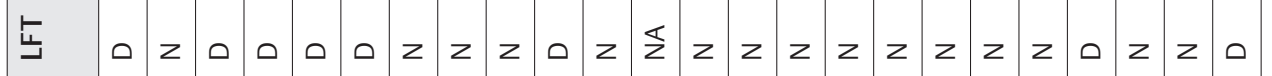
ठำ

$\frac{\widetilde{2}}{\frac{\pi}{m}}$

垈

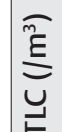

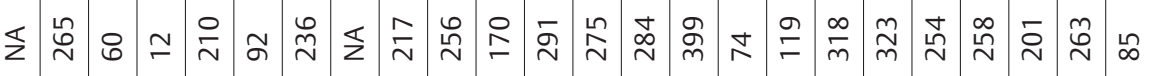

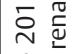
莺运

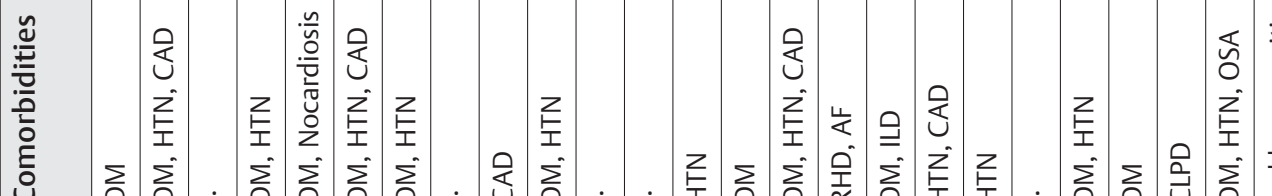

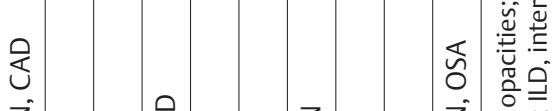

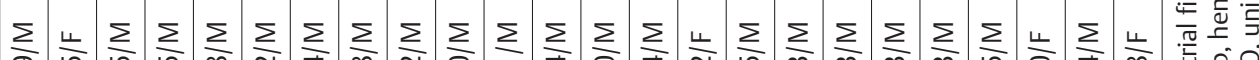




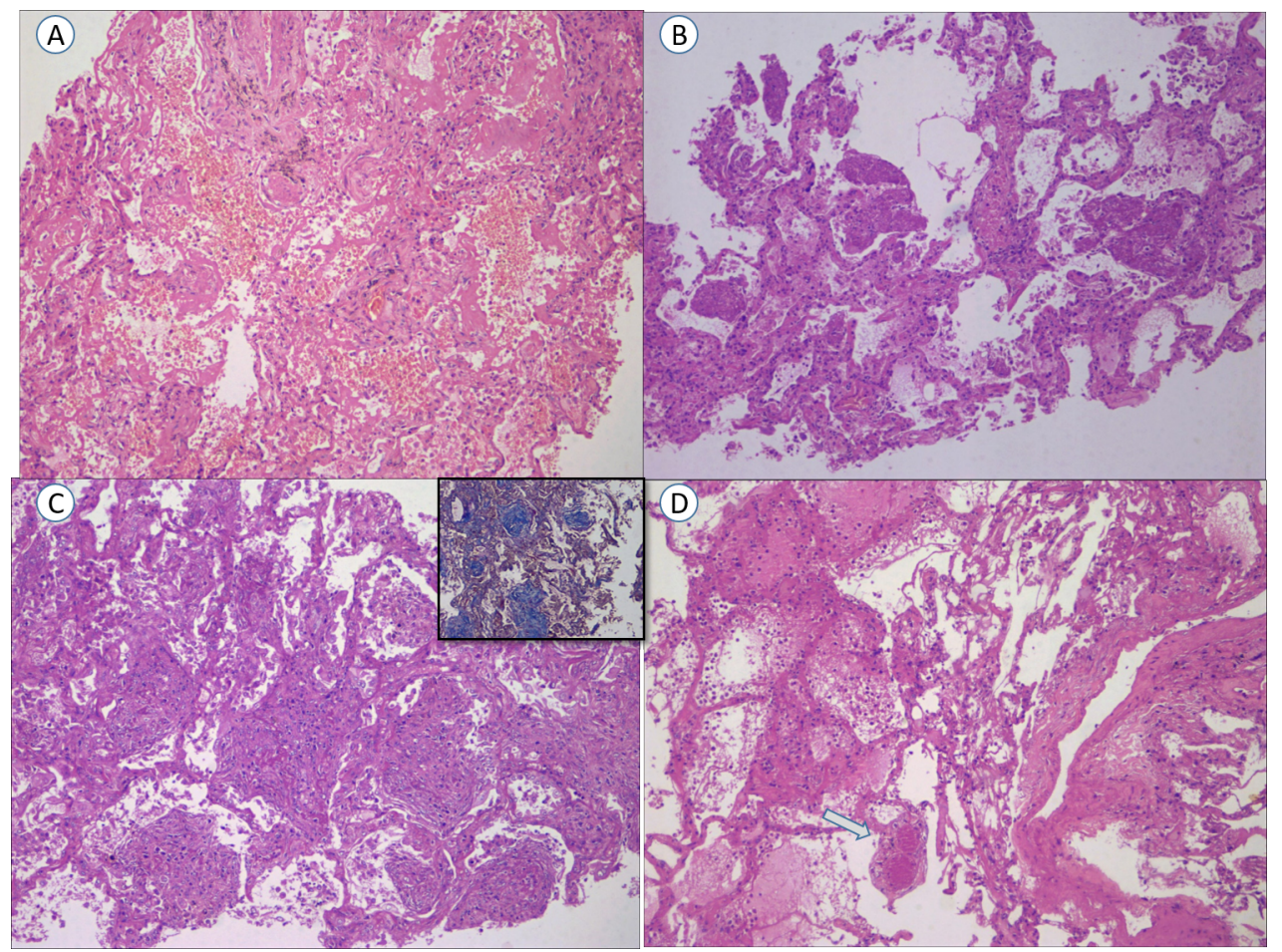

Fig. 1 Pathological findings in lung caused by COVID-19 infection. (A) Exudative phase of DAD characterized by hyaline membrane along terminal airways. (B) Aggregates of fibrin forming ball-like structure within alveolar spaces. (C) Loose fibroblastic plugs within alveoli in organizing phase of DAD (Inset Masson trichrome stain highlighting fibroblastic plug). (D) Microthrombi in small alveolar capillaries (arrow). (A-D, Haematoxylin and Eosin. A-D ×100). COVID-19, coronavirus disease 2019; DAD, diffuse alveolar damage.

Nearly three-fourths (76.2\%) of these cases were $\geq 60$ years with male predominance (M:F ratio was $4: 1$ ). Most cases (85.7\%) had comorbidities in the form of diabetes mellitus (57.1\%) and/or hypertension (47.6\%).

On investigations, nine patients $(42.8 \%)$ had mild anemia, eight (38.1\%) had mild neutrophilic leukocytosis, four (19\%) patients had mild thrombocytopenia, and six (28.6\%) cases had mildly deranged liver function tests. One case of chronic lymphoproliferative disorder revealed lymphocytic leukocytosis. Chest X-rays were done at the time of admission and revealed lung changes in the form of unilateral and bilateral pneumonia with ground glass opacities in 5 (23.8\%) and 14 cases (66.7\%), respectively. Duration of clinical course (symptom onset to death) ranged from 3 to 35 days whereas average duration of hospital stay was 6.9 days (ranging from 2 to 31 days). Nineteen cases had severe disease with $\mathrm{SpO} 2<90 \%$ while two cases had moderate disease with SpO2 approximately $92 \%$. All these cases received anticoagulants (low-molecular weight heparin, subcutaneous) and steroids (dexamethasone). During the course of hospital stay, all cases, except one case with moderate activity, had to be put on mechanical ventilation. The one case with moderate activity had sudden rapid deterioration of the clinical course and died before mechanical ventilation could be instituted. Detailed clinical characteristics, laboratory, and radiological findings are provided in - Table 1 .

\section{Pathological Findings}

Of the 21 confirmed cases subjected to needle biopsies, lung tissue was sampled in 18 cases, liver tissue in 20 cases, and bone marrow in 20 cases.
Histopathological feature of diffuse alveolar damage (DAD) was noted in $88.9 \%$ (16 of 18) cases. Exudative phase, characterized by interstitial edema, loss of type I pneumocytes, and deposition of bright eosinophilic hyaline membrane along the alveolar lining and terminal airways, was identified in $83.3 \%$ (15 of 18 ) cases ( - Fig. 1A). Aggregates of fibrin balls within alveolar spaces, possibly indicating very early phase of DAD and sometimes described as acute fibrinous and organizing pneumonia pattern of injury co-existed in seven cases (-Fig. 1B). Organizing phase characterized by presence of loose fibroblastic plug in the alveolar lumen and early interstitial fibrosis, was identified in $27.7 \%$ (5/18) cases (-Fig. 1C). Pulmonary microthrombi within septal capillaries was seen in $44.4 \%(8 / 18)$ cases ( - Fig. 1D). Other changes of pulmonary parenchyma are summarized in - Table 2. Further, a correlation of histological findings with duration of clinical course was sought. However, no temporal association was noted for the exudative and organizing phase of DAD. We observed organizing phase of DAD as early as 5 days of clinical course while ongoing exudative phase of DAD on 35 days of clinical course. Additionally, foci of bronchopneumonia were noted in two cases (case 5 and case 12) and aspirated material was identified in one case (case 6). On immunohistochemistry, reactive type II pneumocytes were highlighted by TTF- 1 (-Fig. 2A). Squamous metaplasia, seen in $22.2 \%(4 / 18)$ cases, was highlighted by p63 ( - Fig. 2B). A paucity of interstitial chronic inflammatory cells was noted except in $22.2 \%$ (4/18) cases where mild degree of lymphocytic infiltrate was identified. Immunohistochemistry revealed presence

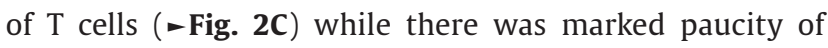


Pathological Findings in COVID-19 Autopsy Vishwajeet et al.

101

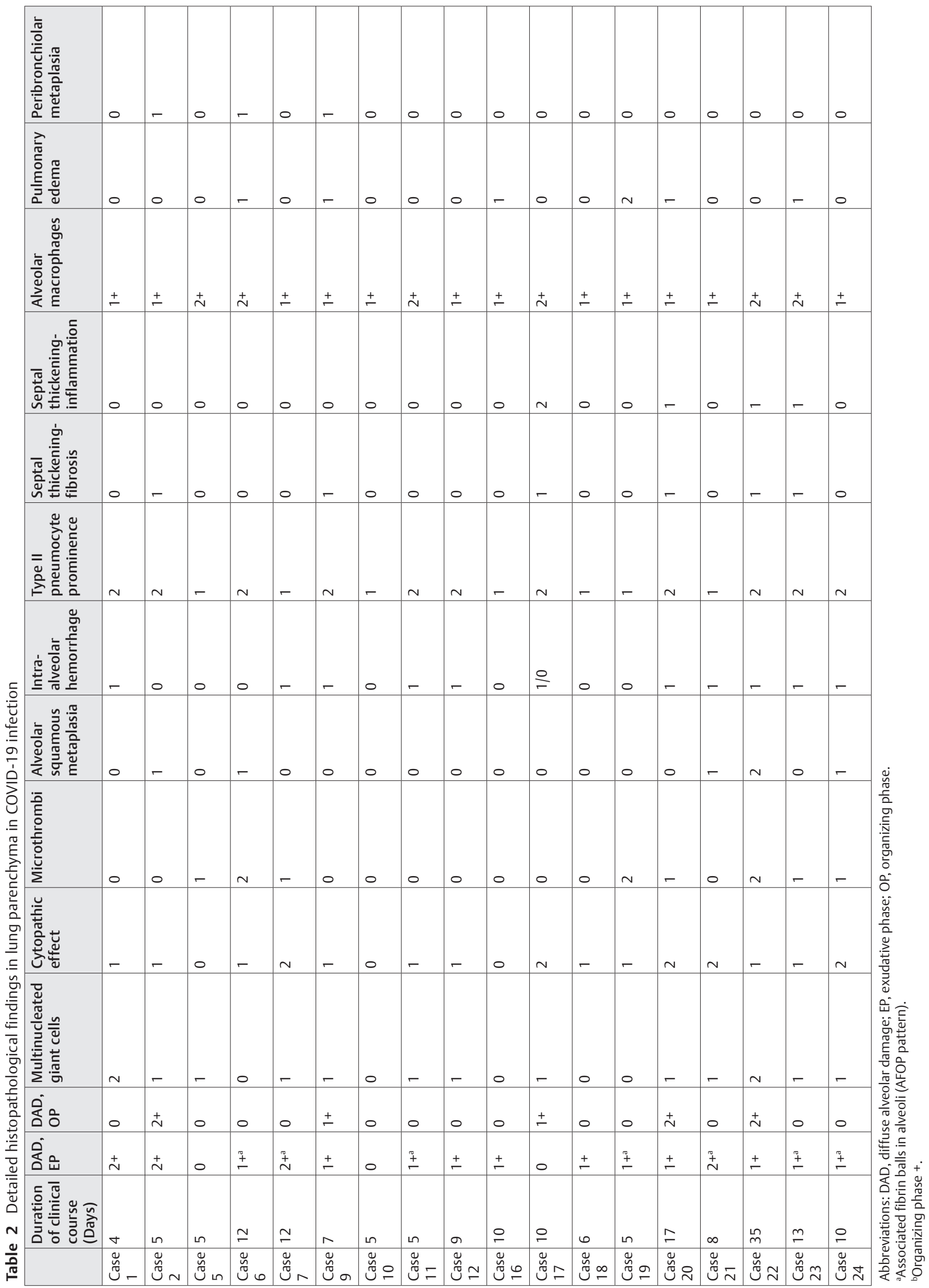

Journal of Laboratory Physicians Vol. 13 No. 2/2021 $\quad$ @ 2021. The Indian Association of Laboratory Physicians. 


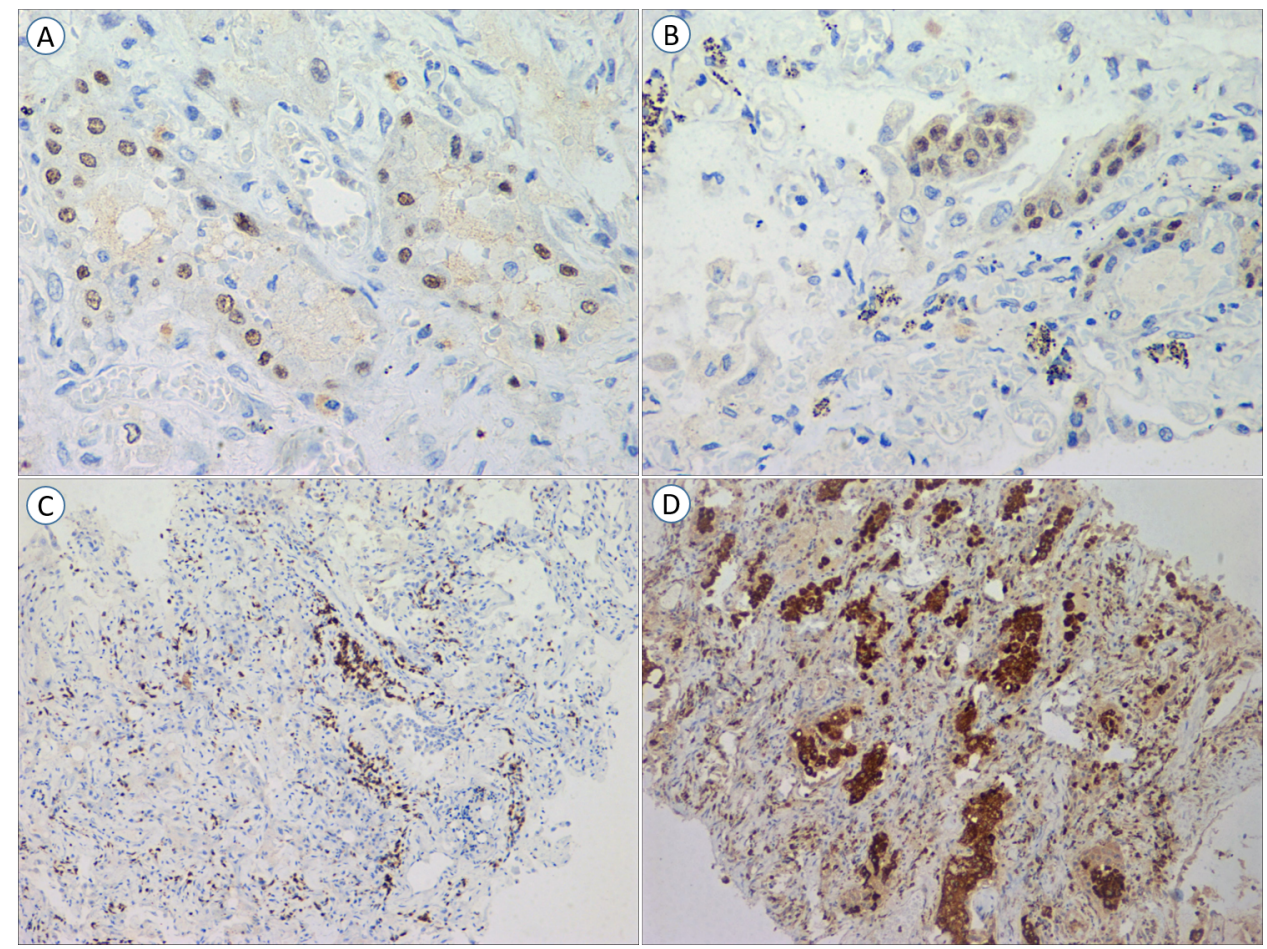

Fig. 2 Immunohistochemistry. (A) TTF-1 shows type II pneumocyte prominence; (B) p63 highlights squamous metaplasia; (C) CD3 shows the presence of T-cells in the alveolar interstitium. (D) CD68 highlights the intra-alveolar collection of macrophages. (A-B $\times 100, C-D \times 400)$.

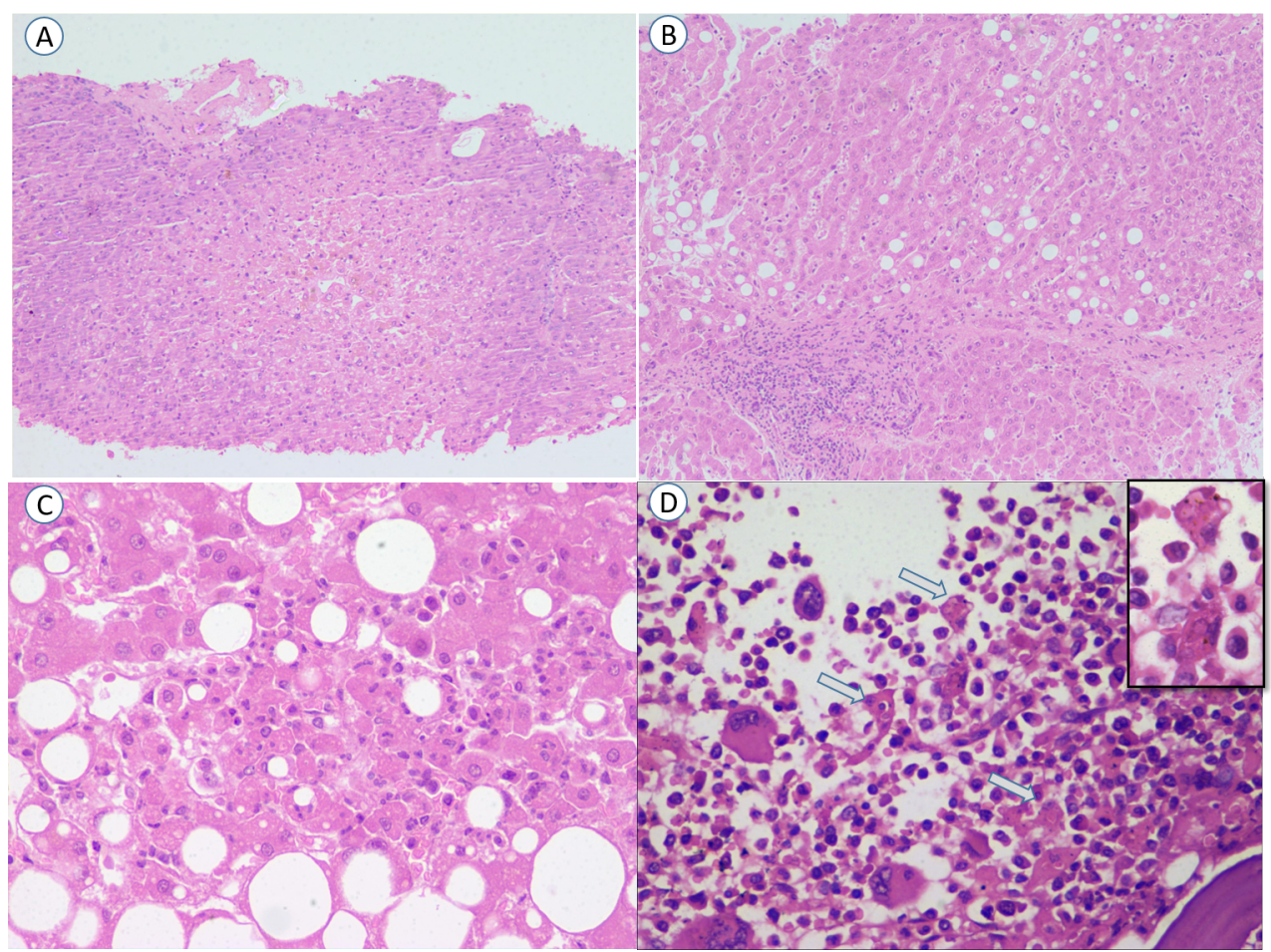

Fig. 3 Pathological findings in liver and bone marrow caused by COVID-19 infection. (A) Centrizonal congestion with hepatocyte loss. (B) Centrizonal congestion with hepatocytic loss. (C) Expanded portal tract with mild degree of lymphocytic cells infiltrate. (D) Increased histiocytes with prominent hemophagocytosis in bone marrow. (A-D, Haematoxylin and Eosin. A-B ×100, C-D ×400). COVID-19, coronavirus disease 2019.

B cells in the alveolar interstitium. CD3 positive $\mathrm{T}$ cells comprised of predominantly CD8 positive cytotoxic cells with a few CD4 positive helper T cells. CD68 highlighted macrophages which were mostly located within alveolar lumina (-Fig. 2D). D-dimer was available in 13 cases and was elevated in 12 cases. The mean value of D-dimer was 
Table 3 Pathological finding in liver in COVID-19 infection

\begin{tabular}{|c|c|c|c|c|c|c|c|c|c|}
\hline & $\begin{array}{l}\text { Portal } \\
\text { Inflammationc }\end{array}$ & $\begin{array}{l}\text { Centrizonal } \\
\text { congestion }\end{array}$ & $\begin{array}{l}\text { Centrizonal } \\
\text { hepato- } \\
\text { cytic loss }\end{array}$ & \begin{tabular}{|l|} 
Sinusoidal \\
dilation \\
with \\
neutrophils
\end{tabular} & $\begin{array}{l}\text { Macrovesicular } \\
\text { steatosis }\end{array}$ & $\begin{array}{l}\text { Lobular } \\
\text { inflamma- } \\
\text { tion }\end{array}$ & Cholestasis & $\begin{array}{l}\text { Glycogenated } \\
\text { nuclei }\end{array}$ & $\begin{array}{l}\text { Kupffer cell } \\
\text { hypertrophy }\end{array}$ \\
\hline Case 1 & b & $\mathrm{a}$ & $\mathrm{a}$ & $a$ & $<10 \%$ & $a, d$ & b & b & a \\
\hline Case 2 & $1+$ & b & $\mathrm{a}$ & $\mathrm{a}$ & $>66 \%$ & $a, d$ & a & b & a \\
\hline Case 5 & b & $\mathrm{a}$ & $b$ & b & b & b & b & b & $a$ \\
\hline Case 6 & b & b & b & b & 60-65\% & $a$ & b & $a$ & b \\
\hline Case 7 & $1+$ & $\mathrm{a}$ & $a$ & $a$ & $40-45 \%$ & $\mathrm{a}$ & b & $\mathrm{a}$ & $a$ \\
\hline Case 9 & $1+$ & b & b & b & $40-45 \%$ & $a$ & $a$ & $a$ & b \\
\hline Case 10 & $1+$ & a & $a$ & $\mathrm{a}$ & $<10 \%$ & a & b & b & a \\
\hline Case 11 & $1+$ & b & b & b & $<10 \%$ & $a$ & b & b & $a$ \\
\hline Case 12 & $1+$ & $a$ & $a$ & $\mathrm{a}$ & $<10 \%$ & $a, d$ & $a$ & b & $a$ \\
\hline Case 13 & b & $\mathrm{a}$ & b & b & $<10 \%$ & b & $\mathrm{a}$ & b & $\mathrm{a}$ \\
\hline Case 14 & b & $a$ & $\mathrm{~b}$ & b & $<10 \%$ & b & $\mathrm{a}$ & $a$ & $\mathrm{a}$ \\
\hline Case 16 & $1+$ & a & a & a & b & $a$ & b & b & $a$ \\
\hline Case 17 & $1+$ & b & b & b & $10-15 \%$ & $\mathrm{a}$ & b & b & b \\
\hline Case 18 & b & b & b & b & $10-15 \%$ & b & $\mathrm{a}$ & b & $a$ \\
\hline Case 19 & b & $\mathrm{b}$ & b & b & $35-40 \%$ & $b$ & b & $\mathrm{a}$ & $\mathrm{a}$ \\
\hline Case 20 & $1+$ & b & b & b & $40-45 \%$ & b & a & b & a,e \\
\hline Case 21 & $b$ & $\mathrm{a}$ & $\mathrm{a}$ & a & $<10 \%$ & a & a & $b$ & $a$ \\
\hline Case 22 & b & b & b & $b$ & $15-20 \%$ & b & $\mathrm{a}$ & b & $a$ \\
\hline Case 23 & $b$ & $a$ & $a$ & a & $>90 \%$ & $a, d$ & b & b & $a$ \\
\hline Case 24 & $1+$ & b & b & a & $15-20 \%$ & $\mathrm{a}$ & b & b & $a$ \\
\hline
\end{tabular}

apresent.

${ }^{\mathrm{b}}$ Absent.

${ }^{\mathrm{c}} 1+$ indicates mild intensity.

dNeutrophilic lobular inflammation.

eKupffer cell hemophagocytosis.

significantly higher in cases showing pulmonary microthrombi $(7.59 \mu \mathrm{g} / \mathrm{mL})$ when compared with the mean value of cases lacking microthrombi $(2.36 \mu \mathrm{g} / \mathrm{mL})$.

The microscopic findings in the liver are summarized in -Table 3. The deranged liver function test did not show significant correlation with any of the histopathological parameters of the liver. ( $p>0.05$, Chi-square test). Portal tract pathology was subtle and was characterized by chronic inflammatory cell infiltrate of mild degree (50\%, 10 cases) ( -Fig. 3A). Porto-portal fibrosis was noted in $15 \%(3 / 20)$ cases. Features attributed to chronic venous congestion were noted in 50\% (10/20) cases in the form of centrizonal congestion (10, 50\% cases) accompanied by hepatocytic loss ( $8,40 \%$

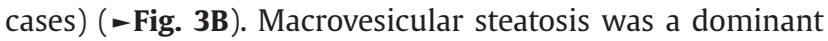
finding and was observed in 90\% (18/20) cases. Cholestasis was noted in $45 \%(9 / 20)$ cases; however, it was focal and intracytoplasmic. Lobular inflammation was observed in $65 \%$ (13/20) cases (lymphocytic lobular inflammation, nine cases and neutrophilic lobular inflammation, four cases) ( - Fig. 3C). The cases with lymphocytic lobular inflammation showed occasional hepatocytic dropout while those with neutrophils showed focal confluent necrosis. CD68 highlighted the Kupffer cell hypertrophy in $85 \%$ (17/20) cases. Two cases had histological features suggestive of nonalcoholic/alcoholic steatohepatitis. Bone marrow showed normocellular $(90 \%$ cases) to mildly hypercellular (10\% cases) marrow spaces. Prominence of histiocytes with hemophagocytosis was reported in 60\% (12/20) cases ( - Fig. 3D).

Of the three cases suspected for COVID-19 but negative on molecular testing, two cases had lung tissue sampled and both cases lacked changes of DAD. Liver, in one case, had cirrhosis while in remaining two cases lacked portal and lobular changes.

\section{Discussion}

Description of pathological findings related to COVID 19 infection has recently begun to be elucidated. ${ }^{6,7}$ These findings provide a glimpse of the pathogenic mechanisms involved in severe COVID-19 infection. In the present study, we report minimally invasive autopsy findings of lungs, liver, and bone marrow in deceased patients with COVID 19. Our study shows the major brunt being on the lung, and also provides evidence of significant liver and bone marrow involvement in severe SARS-CoV-2 infection. 
The most significant microscopic finding observed was acute lung injury in the form of DAD. Similar findings in lung were described during SARS-CoV outbreak of 2002 to 2003 as well as during the current ongoing pandemic of COVID-19.8-15 The first case documenting the histological findings in SARS-CoV-2 infection was published in February 2020 by Xu et al in biopsies from lung, liver, and heart. The authors reported bilateral DAD, multinucleated syncytial cells, and cytopathic changes in pneumocytes. ${ }^{15}$ In a recent large series of 21 cases, the prominent finding noted was exudative (76\%) and organizing DAD (38\%), followed by microthrombi (45\% cases) and pulmonary lymphoid infiltrates and pulmonary hemorrhage, each noted in $14 \%$ cases. ${ }^{16}$ The present study showed the presence of $\mathrm{T}$ lymphocytes (particularly cytotoxic T cells) within the alveolar interstitium as the dominant component of inflammatory cells. It is known that cytotoxic T lymphocytes are helpful to combat acute viral infections in the pulmonary parenchyma. ${ }^{17}$ Barton et al also showed the predominance of cytotoxic $T$ cells in inflammatory infiltrate within the alveolar intersitium. ${ }^{14}$ Menter et al noted pulmonary emboli and vasculitis in 19 and 5\% cases, respectively. ${ }^{16}$ Additionally, the authors reported superimposed bronchopneumonia in nearly half of their cases. ${ }^{16}$ Another recent study described spectrum of histological changes during disease course, with early phase characterized by neutrophilic capillaritis and capillary microthrombi followed by DAD and its subsequent progression to organizing phase..$^{18}$ In the current study, exudative as well as organizing phase of DAD was found, often existing together in $22.2 \%$ cases. We could not find any temporal association for the histological features of lung injury. Instead, organizing phase of DAD was seen as early as 5 days of hospital stay, indicating a subclinical ongoing lung injury before symptoms onset. Abnormal CT findings in asymptomatic cases of COVID 19 are in agreement with this finding. ${ }^{3,19}$ This fact was also highlighted in the study by Bradley et al, where the authors reported histological features of organizing phase of DAD as early as 2 days after symptom onset in a case of fatal COVID-19 infection. ${ }^{12}$ Hence, these findings demand strong clinical suspicion for identifying the patients with ongoing DAD at the time of admission.

In the present study, we found microvascular thrombi in alveolar arterioles in $44.4 \%$ cases. Microthrombi in pulmonary vasculature was demonstrated in several recent studies and ranges from 35.6 to $80 \%{ }^{12-14}$ Presence of microthrombi in significant number of cases in various studies indicated microvascular injury, an important aspect of COVID-19 pathology. A recent study described peculiar vascular features, apart from the acute respiratory distress syndrome, in the form of significant vascular endothelialitis, thrombosis, and neoangiogenesis. The author reported widespread presence of these vascular features, seen in SARS-CoV-2 infections, to be distinct from the H1N1 influenza infections. ${ }^{20}$ Presence of microthrombi in alveolar capillaries was significantly more prevalent in cases with COVID-19, when compared with those of H1N1 influenza infections. ${ }^{20} \mathrm{~A}$ few studies highlighted the role of coagulopathy in the possible causation of widespread thrombosis and disseminated intravascular coagulation. ${ }^{21,22}$
In one of these studies, the author reported pulmonary thromboembolism as cause of death in one-third cases and a high frequency (58\% cases) of unsuspected DVT. ${ }^{21}$ Similarly, Grimes et al described pulmonary emboli as the fatal event in two cases. ${ }^{22}$ In the present study, a significantly higher D-dimer level in cases showing pulmonary microthrombi supports the coagulopathy as a possible cause of thrombosis in pulmonary vessels. The deranged coagulation system is known to occur in association with many other viruses such as HIV, Ebola virus, and dengue virus. ${ }^{23,24}$ Thrombotic events in coronavirus may be triggered by multiple pathogenic mechanisms, including endothelial injury, systemic inflammation, and a procoagulant state..$^{21}$ The histological demonstration of pulmonary microthrombi in the present study supports an important role of vascular thrombotic events in the pathogenesis of COVID-19 pathology.

Theliver pathologyseen in the present study points to different pathogenic mechanisms as described in recent studies. ${ }^{25,26}$ Centrizonal congestion with hepatocytic loss noted in one-half of cases might be related to cardiogenic passive venous congestion as terminal events in severely ill patients, rather than direct insult to liver by viral particles. Significant portal inflammation and prominent cholestatic features were absent in this study, as reported in other case series as well. ${ }^{25-27}$ Sinusoidal dilatation with influx of neutrophils and Kupffer cell prominence seen in present study might represent a hyperinflammatory response/shock-related changes. In this cohort, we found occasional hepatocyte dropout and focal confluent necrosis which might be related to direct viral insult and/or ischemic changes. It has been shown that the biliary epithelial cells express ACE2, a receptor for binding the viral particles, almost comparable to the expression seen in respiratory epithelial cells. ${ }^{28}$ However, in the present study, no definitive or suggestive features of bile duct injury was noted. The same finding was also reported by Sonzogni et al in their cohort of 48 cases with additional steatosis in more than $50 \%$ cases. $^{29}$ The present study also documented steatosis in majority of cases with $38.9 \%$ cases showing moderate ( $>33 \%$ ) to severe ( $>66 \%$ ) degree of steatotic changes. Additionally, a single case, in our study, had prominent hemophagocytosis by Kupffer cell in liver tissue. Thus, it can be derived that liver pathology in COVID-19 infections are attributed to multiple pathogenic events, including circulatory disturbances, ischemic changes, shock-induced changes, and a possible role of direct viral attack. Further, no significant association of any specific pathological parameters with deranged liver function tests was documented. Lagana et al, in their 40 patients, also could not found any association of liver function tests with specific histological changes. ${ }^{25}$ Earlier studies have shown that a significant number of cases with hepatitis B virus infection had considerable histological activity even with normal ALT levels. ${ }^{30}$ However, part of lack of this association in the present study might have been attributed to a small sample size.

A high proportion of cases (60\% cases) showed hyperplasia of histiocytes with prominent hemophagocytosis in bone marrow biopsies. However, no significant pancytopenia was documented in these cases, contrasting with hemophagocytic 
lymphohistiocytosis. There is paucity of literature that documents postmortem marrow findings in these patients. Of the studies published, prominent hemophagocytosis was a common finding. ${ }^{31,32}$ Abnormal cytotoxic T-cell response, triggered by viral infection, resulting in increased release of cytokines and overactivation of histiocytes has been postulated for hemophagocytosis. ${ }^{33}$ Histological presence of hemophagocytosis is described in many conditions, including sepsis, chemotherapy administration, after blood transfusions, and major surgeries and, thus are not very specific for diagnosis of $\mathrm{HLH}^{34}$ Goel et al reported that the presence of marrow hemophagocytosis had a sensitivity of $83 \%$ and specificity of only $60 \%$, for the diagnosis of $\mathrm{HLH} .{ }^{35} \mathrm{An}$ isolated finding of marrow hemophagocytosis in COVID-19 infections should not be considered as evidence of HLH, especially when the supporting clinical presentation and laboratory parameters for $\mathrm{HLH}$ are lacking.

The present study strengthens the view that minimally invasive autopsy is an effective approach to study the pathobiology of the novel infectious agents, where the extent of safety precautions required for performing complete autopsy is not adequate or not known. The procedure can be performed in mortuary rooms lacking laminar air flow and further has advantages of reduced procedure time, minimal aerosol generations and reduced costs. In addition, the relatives of the deceased often refuse to get complete autopsy done, due to their socio-cultural beliefs. In these conditions, the relatives can be offered the options for minimally invasive autopsy. This may enhance the opportunity to study the pathology, where the cause of death remains uncertain.

Our study has several limitations. The most important is lack of complete autopsy. Further, we are not able to comment on the changes of proximal airways, related to sampling issue. Electron microscopy was not performed in the study. Hence, we are not able to demonstrate viral particles in the tissues examined.

\section{Conclusion}

Incorporation of minimally invasive autopsies provides a safe and effective method to study the pathological findings in deceased patients with COVID-19. Presence of pulmonary microthrombi in significant number of cases supports the vascular events, apart from the characteristic DAD, as an important pathogenic mechanism for lung injury in SARS-CoV-2 infection. Higher D-dimer values indicate clinical evidence for underlying microthrombi in circulation. Histopathological findings in liver and bone marrow suggest indirect insult to these organs, related to circulatory and/or hyperinflammatory response to viral infections.

\section{Funding \\ None.}

\section{Authors' Contributions}

V. contributed towards the concept, design, histopathology analysis and interpretation, drafting of manuscript, and critical review of manuscript. A.P. worked on the concept, design, histopathology analysis and interpretation, drafting of manuscript, and final approval of the version. D.K.S. contributed toward the concept, design, clinical management, and drafting of manuscript. S.T. prepared the concept, design, did the sample acquisition, clinical management, and drafting of the manuscript. T.K. contributed toward the concept, design, drafting of manuscript, and critical review of the manuscript. N.D. worked on the concept, design, clinical management, and critical review of manuscript. P.A.E. worked on the concept, design, histopathology analysis and interpretation, drafting of manuscript, and revising it critically for important intellectual content. P.K.B. contributed toward the concept, design, clinical management, and critical review of the manuscript. V.L.N. devoted his time toward the concept, design, microbiology testing, and critical review of manuscript. M.K.G. worked on the concept, design, clinical management, drafting of manuscript, and revising it critically for important intellectual content. S.M. contributed toward the concept, design, revising it critically for important intellectual content, and final approval of the version.

\section{Conflict of Interest}

None declared.

\section{Acknowledgment}

None.

\section{References}

1 Wang C, Horby PW, Hayden FG, Gao GF. A novel coronavirus outbreak of global health concern. Lancet 2020;395(10223): 470-473

2 Coronavirus Outbreak. Available at: https://www.worldometers.info/coronavirus/. Accessed July 21, 2020

3 Andrews MA, Areekal B, Rajesh KR, et al. First confirmed case of COVID-19 infection in India: a case report. Indian J Med Res 2020;151(5):490-492

4 Huang C, Wang Y, Li X, et al. Clinical features of patients infected with 2019 novel coronavirus in Wuhan, China. Lancet 2020;395(10223):497-506

5 Wang $\mathrm{D}, \mathrm{Hu} \mathrm{B}, \mathrm{Hu} \mathrm{C}$, et al. Clinical characteristics of 138 hospitalized patients with 2019 novel coronavirus-infected pneumonia in Wuhan, China. JAMA 2020;323(11):1061-1069

6 Fox SE, Akmatbekov A, Harbert JL. Li G, Quincy Brown J, Vander Heide RS. Pulmonary and cardiac pathology in African American patients with COVID-19: an autopsy series from New Orleans. Lancet Respir Med 2020;8(7):681-686

7 Carsana L, Sonzogni A, Nasr A, et al. Pulmonary post-mortem findings in a series of COVID-19 cases from northern Italy: a two-centre descriptive study. Lancet Infect Dis 2020;20(10): $1135-1140$

8 Borczuk AC, Salvatore SP, Seshan SV, et al. COVID-19 pulmonary pathology: a multi-institutional autopsy cohort from Italy and New York City. Mod Pathol 2020;33(11):2156-2168

9 Konopka KE, Nguyen T, Jentzen JM, et al. Diffuse alveolar damage (DAD) resulting from coronavirus disease 2019 infection is morphologically indistinguishable from other causes of DAD. Histopathology 2020;77(4):570-578

10 Sauter JL, Baine MK, Butnor KJ, et al. Insights into pathogenesis of fatal COVID-19 pneumonia from histopathology 
with immunohistochemical and viral RNA studies. Histopathology 2020;77(6):915-925

11 Nicholls JM, Poon LL, Lee KC, et al. Lung pathology of fatal severe acute respiratory syndrome. Lancet 2003;361(9371): 1773-1778

12 Bradley BT, Maioli H, Johnston R, et al. Histopathology and ultrastructural findings of fatal COVID-19 infections in Washington State: a case series. Lancet 2020;396(10247): 320-332

13 Duarte-Neto AN, Monteiro RAA, da Silva LFF, et al. Pulmonary and systemic involvement in COVID-19 patients assessed with ultrasound-guided minimally invasive autopsy. Histopathology 2020;77(2):186-197

14 Barton LM, Duval EJ, Stroberg E, Ghosh S, Mukhopadhyay S. COVID-19 autopsies, Oklahoma, USA. Am J Clin Pathol 2020;153(6):725-733

$15 \mathrm{Xu} \mathrm{Z}$, Shi L, Wang Y, et al. Pathological findings of COVID-19 associated with acute respiratory distress syndrome. Lancet Respir Med 2020;8(4):420-422

16 Menter T, Haslbauer JD, Nienhold R, et al. Postmortem examination of COVID-19 patients reveals diffuse alveolar damage with severe capillary congestion and variegated findings in lungs and other organs suggesting vascular dysfunction. Histopathology 2020;77(2):198-209

17 Schmidt ME, Varga SM. The CD8 T cell response to respiratory virus infections. Front Immunol 2018;9:678

18 Bösmüller H, Traxler S, Bitzer M, et al. The evolution of pulmonary pathology in fatal COVID-19 disease: an autopsy study with clinical correlation. Virchows Arch 2020;477(3):349-357

19 Shi $\mathrm{H}$, Han $\mathrm{X}$, Jiang $\mathrm{N}$, et al. Radiological findings from 81 patients with COVID-19 pneumonia in Wuhan, China: a descriptive study. Lancet Infect Dis 2020;20(4):425-434

20 Ackermann M, Verleden SE, Kuehnel M, et al. Pulmonary vascular endothelialitis, thrombosis, and angiogenesis in COVID-19. N Engl J Med 2020;383(2):120-128

21 Wichmann D, Sperhake JP, Lütgehetmann M, et al. Autopsy findings and venous thromboembolism in patients with COVID-19: a prospective cohort study. Ann Intern Med 2020;173(4):268-277

22 Grimes Z, Bryce C, Sordillo EM, et al. Fatal pulmonary thromboembolism in SARS-CoV-2-infection. Cardiovasc Pathol 2020;48:107227
23 Antoniak S, Mackman N. Multiple roles of the coagulation protease cascade during virus infection. Blood 2014;123(17):2605-2613

24 Oudkerk M, Büller HR, Kuijpers D, et al. Diagnosis, prevention, and treatment of thromboembolic complications in COVID-19: report of the National Institute for Public Health of the Netherlands. Radiology 2020;297(1):E216-E222

25 Lagana SM, Kudose S, Iuga AC, etal. Hepatic pathology in patients dying of COVID-19: a series of 40 cases including clinical, histologic, and virologic data. Mod Pathol 2020;33(11):2147-2155

26 Wang Y, Liu S, Liu H, et al. SARS-CoV-2 infection of the liver directly contributes to hepatic impairment in patients with COVID-19. J Hepatol 2020;73(4):807-816

27 Beigmohammadi MT, Jahanbin B, Safaei M, et al. Pathological findings of postmortem biopsies from lung, heart, and liver of 7 deceased COVID-19 patients. Int J Surg Pathol 2021;29(2):135-145

28 Li Y, Xiao SY. Hepatic involvement in COVID-19 patients: pathology, pathogenesis, and clinical implications. J Med Virol 2020;92(9):1491-1494

29 Sonzogni A, Previtali G, Seghezzi M, et al. Liver histopathology in severe COVID 19 respiratory failure is suggestive of vascular alterations. Liver Int 2020;40(9):2110-2116

30 Nguyen MH, Garcia RT, Trinh HN, et al. Histological disease in Asian-Americans with chronic hepatitis B, high hepatitis B virus DNA, and normal alanine aminotransferase levels. Am J Gastroenterol 2009;104(9):2206-2213

31 Debliquis A, Harzallah I, Mootien JY, et al. Haemophagocytosis in bone marrow aspirates in patients with COVID-19. Br J Haematol 2020;190(2):e70-e73

32 Prieto-Pérez L, Fortes J, Soto C, et al. Histiocytic hyperplasia with hemophagocytosis and acute alveolar damage in COVID-19 infection. Mod Pathol 2020;33(11):2139-2146

33 Brisse E, Wouters CH, Andrei G, Matthys P. How viruses contribute to the pathogenesis of hemophagocytic lymphohistiocytosis. Front Immunol 2017;8:1102

34 Ho C, Yao X, Tian L, Li FY, Podoltsev N, Xu ML. Marrow assessment for hemophagocytic lymphohistiocytosis demonstrates poor correlation with disease probability. Am J Clin Pathol 2014;141(1):62-71

35 Goel S, Polski JM, Imran H. Sensitivity and specificity of bone marrow hemophagocytosis in hemophagocytic lymphohistiocytosis. Ann Clin Lab Sci 2012;42(1):21-25 